\title{
Energy intake, physical activity and body weight: a simulation model
}

\author{
BY KLAAS R. WESTERTERP ${ }^{1}$, JEROEN H. H. L. M. DONKERS ${ }^{2}$, \\ ELISABETH W. H. M. FREDRIX ${ }^{3}$ AND PIET BOEKHOUDT ${ }^{4}$ \\ ${ }^{1}$ Department of Human Biology, ${ }^{2}$ Department of Medical Informatics, and ${ }^{4}$ Department of \\ Mathematics, University of Limburg, PO Box 616, 6200 MD Maastricht, The Netherlands \\ ${ }^{3}$ Department of Natural Sciences, Open University, Heerlen, The Netherlands
}

(Received 30 June 1993 - Revised 5 July 1994 - Accepted 7 July 1994)

\begin{abstract}
In adults, body mass (BM) and its components fat-free mass (FFM) and fat mass (FM) are normally regulated at a constant level. Changes in FM and FFM are dependent on energy intake (EI) and energy expenditure (EE). The body defends itself against an imbalance between $E I$ and $E E$ by adjusting, within limits, the one to the other. When, at a given EI or EE, energy balance cannot be reached, FM and FFM will change, eventually resulting in an energy balance at a new value. $A$ model is described which simulates changes in FM and FFM using EI and physical activity (PA) as input variables. EI can be set at a chosen value or calculated from dietary intake with a database on the net energy of foods. PA can be set at a chosen multiple of basal metabolic rate (BMR) or calculated from the activity budget with a database on the energy cost of activities in multiples of BMR. BMR is calculated from FFM and FM and, if necessary, FFM is calculated from BM, height, sex and age, using empirical equations. The model uses existing knowledge on the adaptation of energy expenditure (EE) to an imbalance between EI and EE, and to resulting changes in FM and FFM. Mobilization and storage of energy as FM and FFM are functions of the relative size of the deficit (EI/EE) and of the body composition. The model was validated with three recent studies measuring EE at a fixed EI during an interval with energy restriction, overfeeding and exercise training respectively. Discrepancies between observed and simulated changes in energy stores were within the measurement precision of EI, EE and body composition. Thus the consequences of a change in dietary intake or a change in physical activity on body weight and body composition can be simulated.
\end{abstract}

Energy intake: Physical activity: Simulation model

Body mass (BM) in adult man is regulated at a constant level, an everyday experience backed by surprisingly little data in the literature. One of the few studies providing information on the constancy of BM is the Framingham Study, a long-term sampling of 5209 adults, 30-59 years of age, living in the town of Framingham at the start of the study from 1948 to 1949 . They underwent, every 2 years, a standard medical examination, including the measurement of BM, for at least 20 years if not prevented by illness or death. Most subjects lost or gained no more than 5-10 kg over some part of the 20 -year period as calculated by James (1985). This demonstrates a nearly perfect system for preserving energy balance as the total energy turnover of an average adult subject over 20 years is $73000 \mathrm{MJ}$. A discrepancy of $1 \%$ between energy intake (EI) and energy expenditure (EE) would add up to $730 \mathrm{MJ}$ over 20 years, equivalent to about $24 \mathrm{~kg} \mathrm{BM}$ as fat tissue with an energy density of $30 \mathrm{MJ} / \mathrm{kg}$. Thus, in the long term EI matches EE within $1 \%$.

There are situations where subjects are brought into a positive or negative energy balance by an intervention and where one wants to know the resulting consequences for BM. Examples are overeating or undereating and a restriction of physical activity or exercise 
training. The consequences of the intervention for energy balance are not a linear function of the size of the intervention and are not linear over time. Reducing EI by $1 \mathrm{MJ} / \mathrm{d}$ or increasing EE by $1 \mathrm{MJ} / \mathrm{d}$ by eating less at the same level of physical activity or exercising more at the same level of EI respectively does not result in a BM loss of $1 \mathrm{~kg}$ over $30 \mathrm{~d}$, using an energy equivalent of $30 \mathrm{MJ} / \mathrm{kg}$ as mentioned above. The BM loss is smaller as the body defends itself against a negative energy balance. A negative energy balance results in a reduction of basal metabolic rate (BMR) through a loss of $\mathrm{BM}$ and a reduction of $\mathrm{EE}$ per unit BM. The opposite holds as well: increasing EI by $1 \mathrm{MJ} / \mathrm{d}$ or reducing EE by $1 \mathrm{MJ} / \mathrm{d}$ by eating more at the same level of physical activity or exercising less at the same level of EI respectively does not result in a BM gain of $1 \mathrm{~kg}$ over $30 \mathrm{~d}$. A positive energy balance results in an increase of BMR through an increase of BM. An increase of EE per unit BM, i.e. as a consequence of so-called futile cycles, has not been shown.

We will describe a model which uses existing knowledge on the relationship between EI, fat-free mass (FFM) and fat mass (FM), and EE in energy balance, and on the adaptation of EE to a changing EI, to a changing activity budget, and to resulting changes in FM and FFM. Thus the consequences of a change in dietary intake or a change in physical activity on FM and FFM can be simulated.

\section{METHODS}

The model is a continuous-time dynamic mathematical model. Input variables are energy intake $(\mathrm{EI})$ and energy expenditure $(\mathrm{EE})$. When EI does not match $\mathrm{EE}$, energy is stored in or mobilized from the body assuming two compartments: fat mass (FM) and fat-free mass (FFM). The two input variables and the resulting consequences when EI does not match EE will be described separately.

\section{Energy intake}

EI, as an input variable, is estimated or can be calculated from information on dietary intake as collected with e.g. a dietary recall or a dietary record. The energy content of the diet is calculated with a nutrient table in a separate database (Stichting Nederlands Voedingsstoffenbestand, 1989). The resulting figure is the net energy intake, i.e. gross energy intake corrected for energy losses in faeces and urine, available for energy production.

\section{Energy expenditure}

$\mathrm{EE}$ is the sum of diet-induced energy expenditure (DEE) and physical activity (PA), i.e.

$$
\mathrm{EE}(\mathrm{t})=\mathrm{DEE}(\mathrm{t})+\mathrm{PA}(\mathrm{t})
$$

where $t$ is time in days. DEE is estimated at $10 \% \mathrm{EI}$ (Schutz et al. 1984), i.e.

$$
\operatorname{DEE}(\mathrm{t})=0 \cdot 1 \mathrm{EI}(\mathrm{t})
$$

PA, as an input variable, is estimated or can be calculated from information on the activity budget as collected with e.g. an activity recall or an activity record. The activity budget is converted to PA with the energy cost of the activities expressed as a multiple of BMR, i.e.

$$
\operatorname{PA}(\mathrm{t})=\alpha(\mathrm{t}) \operatorname{BMR}(\mathrm{t}),
$$

where $\alpha$ is the physical activity factor. The value of the factor $\alpha(\geqslant 1)$, which is also an input of the system, for a range of physical activities is stored in a separate database (Ainsworth et al. 1993). For BMR the following empirical expression is used (see Appendix 1):

$$
\operatorname{BMR}(\mathrm{t})=0 \cdot 102 F F M(t)+0 \cdot 024 F M(t)+0 \cdot 85
$$


In a negative energy balance there is a lowering of BMR per unit BM depending on the size of the energy deficit. EE is lowered by an energy expenditure reduction (EER):

$$
\operatorname{EER}(t)=e(t) \operatorname{PA}(t) .
$$

The value of e, which value is a function of EI/EE, ranges from $0 \cdot 0$ to $0 \cdot 1$ (James et al. 1990):

$$
e(t)=\left\{\begin{array}{ccc}
0 & \text { for } & (\operatorname{EI}(t) / E E(t)) \geqslant 1 \\
0 \cdot 1 & \text { for } & (\operatorname{EI}(t) / \operatorname{EE}(t)) \leqslant 0 \cdot 5 \\
0 \cdot 2(1-(\operatorname{EI}(t) / \operatorname{EE}(t)) & \text { for } & 0 \cdot 5<(\operatorname{EI}(t) / \operatorname{EE}(t))<1 .
\end{array}\right.
$$

\section{Energy storage and mobilization}

In a positive energy balance situation the energy surplus is stored and EE goes up because when an energy surplus is stored it has to be converted to a suitable compound, i.e. carbohydrate is deposited as glycogen or fat, fat is deposited as fat, and protein is deposited as protein, glycogen or fat. The conversion cost (EC) is estimated at a mean value of $10 \%$ of the energy surplus (Stock \& Rothwell, 1982), close to the cost of depositing fat surplus as body fat, by far the most important process to store an energy surplus.

$$
E C(t)=h(t)(E I-E E(t)),
$$

where the conversion cost factor $\mathrm{h}$ is defined as:

$$
h(t)=\left\{\begin{array}{ccc}
0 & \text { for } & E I(t) \leqslant E E(t) \\
0 \cdot 1 & \text { for } & E I(t)>E E(t) .
\end{array}\right.
$$

Thus, the energy balance (EB) is:

$$
E B(t)=E I-E E(t)+E E R(t)-E C(t) .
$$

The change per day of FM and FFM depends on EB. The energy densities of FM and FFM are assumed to be $38 \mathrm{MJ} / \mathrm{kg}$ and $6 \mathrm{MJ} / \mathrm{kg}$ respectively, based on the energy density of fat and protein and FM being pure fat and FFM being $73 \%$ water and $27 \%$ protein. The ratio of mobilization or storage of energy between FM and FFM is not a constant (Forbes, 1987; Prentice et al. 1991). When EI exceeds EE excess energy is stored as FM and FFM in a ratio which is a linear function of the body composition. The surplus is stored as FM and FFM in a mass ratio of $75: 25$ or in an energy ratio of $95: 5$. When EI is lower than EE the energy deficit is covered from FM and FFM in a ratio which is a linear function of the relative size of the deficit (EI:EE) and of the body composition. In a situation where EI:EE is between 1 and 0.5 and where FM is higher than $7.5 \%$ and $15 \%$ of BM in males and females respectively, the deficit is mobilized from FM and FFM in a mass ratio of 75:25 or in an energy ratio of $95: 5$. When EI:EE is lower than 0.5 and/or FM is lower than $7.5 \%$ and $15 \%$ of $\mathrm{BM}$ in males and females respectively, relatively more energy is mobilized from FFM linearly increasing up to $100 \%$ FFM. There is a minimum FM of $3 \%$ BM for both males and females representing structural fat. Thus, the model is a system of two ordinary differential equations:

$$
\left\{\begin{array}{l}
\frac{d \mathrm{FM}(\mathrm{t})}{d \mathrm{t}}=\frac{\mathrm{fef}(\mathrm{t}) \mathrm{EB}(\mathrm{t})}{f m_{e d}}, \\
\frac{d \mathrm{FFM}(\mathrm{t})}{d \mathrm{t}}=\frac{(1-\mathrm{fef}(\mathrm{t})) \mathrm{EB}(\mathrm{t})}{f f m_{e d}},
\end{array}\right.
$$

where the change per day of FM and FFM depends on EB, the fat energy factor (fef), which 

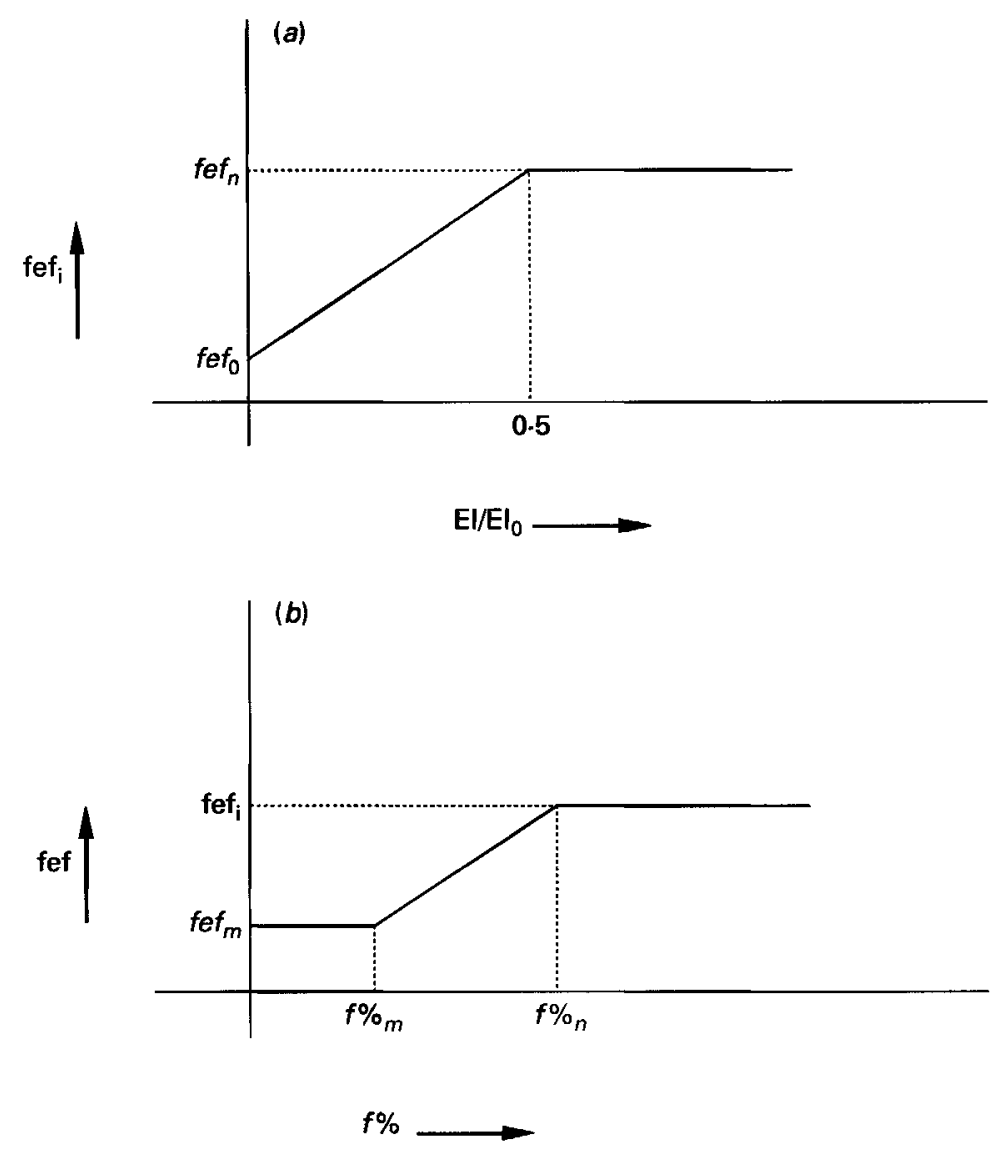

Fig. 1. Computation of $(a)$ intermediate fat energy factor (fef $f_{\mathbf{i}}$ and $(b)$ fat energy factor (fef). For definition of parameters and variables, see Table 1.

determines which part of the energy balance is transformed to FM, and fat mass energy density $\left(f m_{e d}\right)$ and fat-free mass energy density $\left(f f m_{e d}\right)$.

For the computation of the fat energy factor (fef) we need a measure for being out of equilibrium $(E B(t)=0)$. Let $E I$ be the actual energy intake and $\mathrm{EI}_{0}(t)$ the energy intake to achieve $\mathrm{EB}(\mathrm{t})=0$, which means that EI equals EE. From equations (1), (2) and (3) it follows that:

$$
\begin{aligned}
\mathrm{EI}_{0}(\mathrm{t}) & =\mathrm{EE}(\mathrm{t}) \\
& =0 \cdot 1 \mathrm{EI}_{0}(\mathrm{t})+\alpha(\mathrm{t}) \operatorname{BMR}(\mathrm{t}), \\
\mathrm{EI}_{0}(\mathrm{t}) & =\alpha(\mathrm{t}) \operatorname{BMR}(\mathrm{t}) / 0 \cdot 9 .
\end{aligned}
$$

The fat energy factor (fef) is computed in a two-stage procedure (Fig. 1).

Stage 1: computation of an intermediate fef $\left(\mathrm{fef}_{1}\right)$,

$$
\mathrm{fef}_{\mathrm{i}}(\mathrm{t})=\left\{\begin{array}{ccc}
f e f_{n} & \text { for } & \left(\mathrm{EI}(\mathrm{t}) / \mathrm{EI}_{0}(\mathrm{t})\right) \geqslant 0.5 \\
2\left(f e f_{n}-f e f_{0}\right) \cdot\left(\mathrm{EI}(\mathrm{t}) / \mathrm{EI}_{0}(\mathrm{t})\right)+f e f_{0} & \text { for } & 0 \leqslant\left(\mathrm{EI}(\mathrm{t}) / \mathrm{EI}_{0}(\mathrm{t})\right)<0.5
\end{array}\right.
$$

where the factor $f e f_{n}$ is the normal fat energy factor and the factor $f e f_{0}$ is the energy factor which is found for $\mathbf{E I}=\mathbf{0}$. 
Table 1. Summary of parameters and variables

\begin{tabular}{|c|c|c|c|}
\hline Parameter & Meaning & Value & Unit \\
\hline$f e f_{m}$ & minimal fat energy factor & 0 & - \\
\hline$f e f_{n}$ & normal fat energy factor & 0.95 & - \\
\hline$f e f_{0}$ & fef for energy intake $=0$ & $0 \cdot 9$ & - \\
\hline$f f m_{e d}$ & fat-free mass energy density & 6 & $\mathrm{MJ} / \mathrm{kg}$ \\
\hline$f m_{e d}$ & fat mass energy density & 38 & $\mathrm{MJ} / \mathrm{kg}$ \\
\hline$f \%_{m}$ & minimal fat percentage & & - \\
\hline$f \%_{n}$ & normal fat percentage & men $7 \cdot 5$, women 15 & - \\
\hline Variable & Meaning & $\begin{array}{l}\text { Definition } \\
\text { (equation number) }\end{array}$ & Unit \\
\hline$\alpha$ & physical activity factor & input variable & - \\
\hline e & BMR-reduction factor & (6) & - \\
\hline fef & fat energy factor & (14) & - \\
\hline $\mathrm{fef}_{\mathrm{i}}$ & intermediate fat energy factor & (13) & - \\
\hline$f \%$ & fat percentage & $100 \% \cdot F M /(F M+F F M)$ & - \\
\hline $\mathrm{h}$ & conversion cost factor & (8) & - \\
\hline $\mathrm{t}$ & time & - & $d$ \\
\hline BMR & basal metabolic rate & (4) & $\mathrm{kJ}$ \\
\hline DEE & diet-induced energy expenditure & (2) & $\mathrm{kJ}$ \\
\hline EB & energy balance & (9) & $\mathrm{kJ}$ \\
\hline $\mathrm{EC}$ & conversion cost & (7) & $\mathrm{kJ}$ \\
\hline EE & energy expenditure & (1) & $\mathbf{k J}$ \\
\hline EER & energy expenditure reduction & (5) & $\mathrm{kJ}$ \\
\hline EI & energy intake & input variable & $\mathrm{kJ}$ \\
\hline $\mathrm{EI}_{0}$ & 'equilibrium' energy intake & & $\mathrm{kJ}$ \\
\hline FFM & fat-free mass & $(10 b)$ & $\mathrm{kg}$ \\
\hline FM & fat mass & $(10 a)$ & $\mathrm{kg}$ \\
\hline PA & physical activity & (4) & $\mathrm{kJ}$ \\
\hline
\end{tabular}

Stage 2: computation of $f e f$,

$$
\text { fef(t) }=\left\{\begin{array}{cccc}
\mathrm{fef}_{\mathrm{i}}(\mathrm{t}) & \text { for } & f \%>f \%_{n} \\
f e f_{m}+\left(\mathrm{fef}_{\mathrm{i}}(\mathrm{t})-f e f_{m}\right)\left(f \%^{2}-f \%_{m}\right) /\left(f \%_{n}-f \%_{m}\right) & \text { for } & f \%_{m} \leqslant f \% \leqslant f \%_{n} \\
f e f_{m} & \text { for } & f \% \leqslant f_{m}
\end{array}\right.
$$

where $f \%$ is the fat percentage, $f \%_{n}$ the normal fat percentage, $f \%_{m}$ the minimal fat percentage and $f e f_{m}$ the minimal fat energy factor. A summary of all variables and parameters is given in Table 1.

\section{RESULTS}

A simulation usually starts from energy balance $(E I=E E)$. When $E I$ or $E E$ is measured, $\mathrm{EE}$ and $\mathrm{EI}$ respectively can be matched to reach energy balance. When both EI and EE are measured there is usually a discrepancy and energy balance can only be reached by a manipulation of the data. A realistic starting point for a manipulation of the data is the knowledge that EE normally ranges between 1.2 BMR (Apfelbaum, 1978; Waterlow, 1986) and 2.2 BMR (Westerterp et al. 1992a), and has a value of 1.7 BMR for a subject with a moderate level of physical activity (World Health Organization, 1985 and Appendix 1). Subjects in the upper or lower parts of the range should know themselves as being, respectively, somebody with an above average or below average level of physical activity.

Theoretical predictions of the model can be compared with experimental evidence. 
Table 2. Body mass $(B M)$ and fat mass $(F M)$ in seven men before and after $21 d$ energy restriction (by $3.4 \mathrm{MJ} /$ d) as reported by Heyman et al. (1992) compared with the results of the simulation model

\begin{tabular}{|c|c|c|c|c|c|c|}
\hline & & & \multicolumn{4}{|c|}{ After $21 \mathrm{~d}$ energy restriction } \\
\hline & \multicolumn{2}{|c|}{ Baseline } & \multicolumn{2}{|c|}{ Observed } & \multicolumn{2}{|c|}{ Simulated } \\
\hline & $\begin{array}{l}\text { BM } \\
\text { (kg) }\end{array}$ & $\begin{array}{l}\text { FM } \\
\text { (kg) }\end{array}$ & $\begin{array}{l}\text { BM } \\
(\mathrm{kg})\end{array}$ & $\begin{array}{l}\mathrm{FM} \\
(\mathrm{kg})\end{array}$ & $\begin{array}{l}\text { BM } \\
(\mathrm{kg})\end{array}$ & $\begin{array}{l}F M \\
(\mathrm{~kg})\end{array}$ \\
\hline Mean $(n 7)$ & $69 \cdot 2$ & $9 \cdot 1$ & $67 \cdot 2$ & $8 \cdot 0$ & 67.5 & 7.8 \\
\hline
\end{tabular}

Manipulations of energy balance inducing weight loss include studies with weight-reducing diets. On the other hand there are a number of studies describing weight gain after an experimental increase in EI. Studies describing the long-term effect of a manipulation of the level of physical activity on energy balance are scarce. Very few studies include observations on all three components of the energy balance equation: EI, EE, and FM and FFM. EI can be measured with sufficient accuracy with a fully weighed dietary record or with full provision of the diet. EE can be measured with sufficient accuracy in a respiration chamber or with doubly-labelled water. Acceptable methods for measuring changes in FM and FFM include hydrodensitometry and isotope dilution. Using these criteria there is currently one study on the effect of energy restriction, one study on overfeeding, and one study on the effect of an increase in physical activity.

Heyman et al. (1992) fed seven men at a level of $3.4 \mathrm{MJ} / \mathrm{d}$ below baseline requirements for $21 \mathrm{~d}$. Baseline EI to maintain BM was determined over $10 \mathrm{~d}$. The resulting mean EI of $15 \cdot 3 \mathrm{MJ} / \mathrm{d}$ was very close to the measured $\mathrm{EE}$ with doubly-labelled water of $15.4 \mathrm{MJ} / \mathrm{d}$ over the $10 \mathrm{~d}$ interval. Subsequently EI was decreased by $3.4 \mathrm{MJ} / \mathrm{d}$ resulting in an EE of $14.7 \mathrm{MJ} / \mathrm{d}$ and $13.6 \mathrm{MJ} / \mathrm{d}$ over the first and the second $10 \mathrm{~d}$ intervals of energy restriction respectively. The level of PA expressed as EE/BMR showed a non-significant decrease from $2 \cdot 1(\mathrm{SE} 0 \cdot 1)$ to $2 \cdot 0(\mathrm{SE} 0 \cdot 2)$. Table 2 shows the relevant parameters before the intervention and at $21 \mathrm{~d}$ after the start of the intervention as measured and simulated with the model.

Diaz et al. (1992) overfed nine men by $50 \%$ above baseline requirements with a mixed diet for $42 \mathrm{~d}$. Subjects were in energy balance in the baseline period of 3 weeks. Mean EI, calculated from the food supplied using food composition tables, was $13.3 \mathrm{MJ} / \mathrm{d}$ and mean EE, measured over the second and third weeks with doubly-labelled water, was $13 \cdot 2 \mathrm{MJ} / \mathrm{d}$. EE minus EI was 1 (SD 9) \%. Subsequently EI was increased to $19.6 \mathrm{MJ} / \mathrm{d}$, resulting in an $\mathrm{EE}$ of $15.0 \mathrm{MJ} / \mathrm{d}$ over weeks 6 and 7 of the 7 -week overfeeding interval. The level of PA expressed as EE/BMR was 1.8 (SD 0.2$)$ in the baseline period and remained unchanged. Table 3 shows the relevant parameters before the intervention and at $42 \mathrm{~d}$ after the start of the intervention as measured and simulated with the model.

Bingham et al. (1989) trained sedentary subjects, two women and three men, keeping EI at the level for maintenance of BM as measured in a 3-5-week control period before the start of the training. At the end of the 9-week training the subjects were capable of running for $1 \mathrm{~h} / \mathrm{d}, 5 \mathrm{~d} /$ week. The level of PA expressed as EE/BMR, measured with a doublylabelled water (EE) and in a respiration chamber (BMR) in the baseline period and over the last 2 weeks of the training, increased from 1.6 (SD 0.1 ) to 1.7 (SD 0.1 ) for the women and from $1.6(S D 0.1)$ to 2.2 (SD 0.2 ) for the men. Table 4 shows the relevant parameters before 
Table 3. Body mass (BM) and fat mass (FM) in eight men before and after 42 d overfeeding (by 6.6 MJ/d) as reported by Diaz et al. (1992) compared with the results of the simulation model

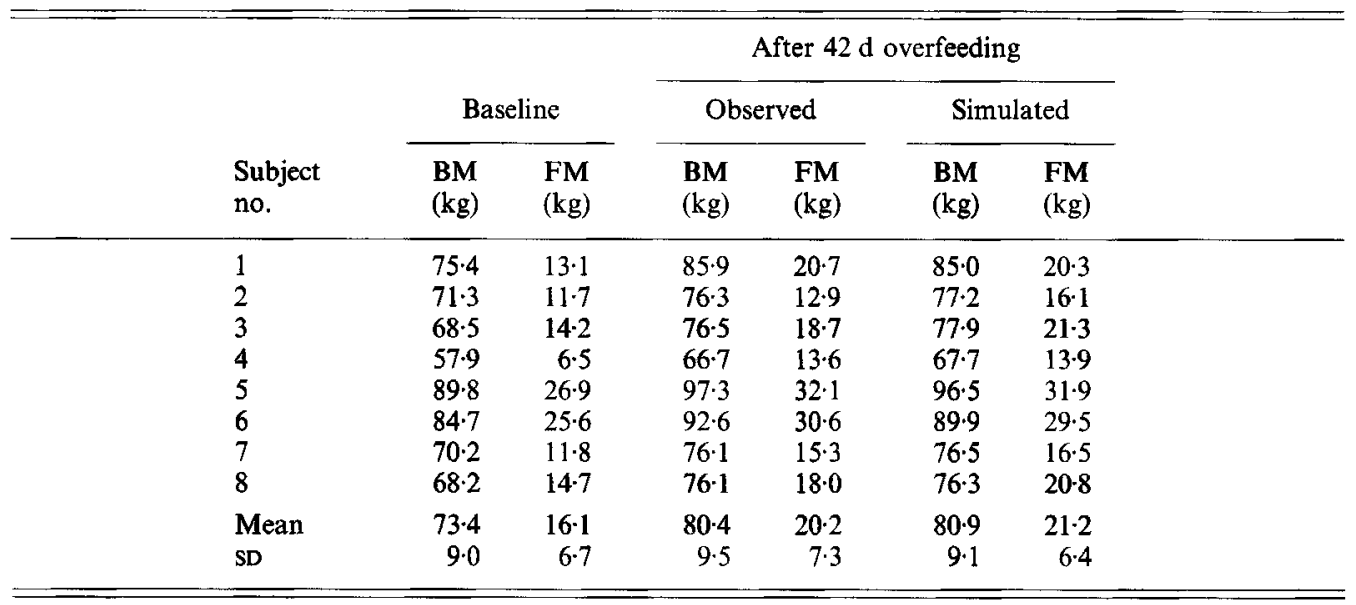

Table 4. Body mass (BM) and fat mass (FM) in two women and three men before and after $63 \mathrm{~d}$ exercise training (increasing the average daily metabolic rate by $1 \mathrm{MJ} / \mathrm{d}$ in women and $4 \mathrm{MJ} / \mathrm{d}$ in men) as reported by Bingham et al. (1989) compared with the results of the simulation model

\begin{tabular}{|c|c|c|c|c|c|c|c|}
\hline \multirow[b]{3}{*}{$\begin{array}{l}\text { Subject } \\
\text { no. }\end{array}$} & \multirow[b]{3}{*}{ Sex } & & & \multicolumn{4}{|c|}{ After $63 \mathrm{~d}$ exercise training } \\
\hline & & \multicolumn{2}{|c|}{ Baseline } & \multicolumn{2}{|c|}{ Observed } & \multicolumn{2}{|c|}{ Simulated } \\
\hline & & $\begin{array}{l}\text { BM } \\
(\mathrm{kg})\end{array}$ & $\begin{array}{l}\text { FM } \\
(\mathrm{kg})\end{array}$ & $\begin{array}{l}\text { BM } \\
(\mathrm{kg})\end{array}$ & $\begin{array}{l}\text { FM } \\
(\mathrm{kg})\end{array}$ & $\begin{array}{l}\mathrm{BM} \\
(\mathrm{kg})\end{array}$ & $\begin{array}{l}\text { FM } \\
(\mathrm{kg})\end{array}$ \\
\hline 1 & f & $51 \cdot 2$ & $15 \cdot 4$ & $52 \cdot 3$ & $15 \cdot 6$ & $53 \cdot 4$ & $16 \cdot 8$ \\
\hline 2 & f & $66 \cdot 5$ & $20 \cdot 0$ & $66 \cdot 7$ & $18 \cdot 0$ & $62 \cdot 6$ & $17 \cdot 1$ \\
\hline 3 & $\mathbf{m}$ & $64 \cdot 4$ & $10 \cdot 6$ & $63 \cdot 2$ & $10 \cdot 0$ & $64 \cdot 7$ & $10 \cdot 7$ \\
\hline 4 & $\mathbf{m}$ & $68 \cdot 4$ & $7 \cdot 3$ & $68 \cdot 0$ & 4.9 & $59 \cdot 7$ & $2 \cdot 4$ \\
\hline 5 & $\mathrm{~m}$ & $63 \cdot 8$ & $8 \cdot 2$ & $60 \cdot 4$ & $3 \cdot 7$ & $60 \cdot 0$ & 5.9 \\
\hline Mean & & $62 \cdot 9$ & $12 \cdot 3$ & $62 \cdot 1$ & $10 \cdot 4$ & $60 \cdot 1$ & $10 \cdot 6$ \\
\hline $\mathrm{SD}$ & & $6 \cdot 8$ & $5 \cdot 3$ & $6 \cdot 2$ & $6 \cdot 3$ & $1 \cdot 3$ & $6 \cdot 5$ \\
\hline
\end{tabular}

the intervention and at $63 \mathrm{~d}$ after the start of the intervention as measured and simulated with the model.

The model is applicable to predict the effect of a planned intervention to change EI and EE on FM and FFM. The other way around, it allows calculation of EI and EE to reach a planned value of FM and FFM at a given time interval. Finally, the model can provide information on the energy balance under normal circumstances. Two examples are given, one for the consequences of a planned intervention to change EI and EE on FM and FFM, the other one for the information this model can provide on energy balance under normal circumstances. In one study it was planned to reduce dietary fat intake by one third in 


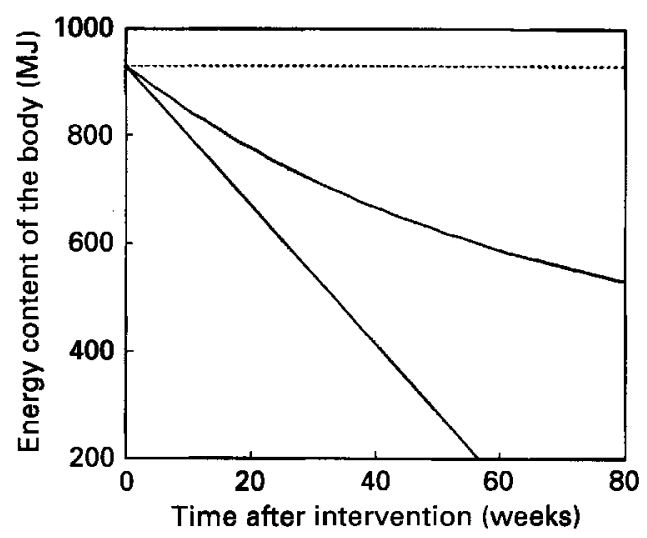

Fig. 2. Changes in the energy content of the body for a man weighing $75 \mathrm{~kg}$, with $20 \%$ body fat at a daily energy intake equal to a daily energy expenditure of $13 \mathrm{MJ}$, after reduction of energy intake by $1.8 \mathrm{MJ} / \mathrm{d}$, assuming no changes in physical activity. Upper line: result of the simulation model; lower line: result without adaptive changes in energy expenditure For details, see pp. 343-344.

subjects consuming a Western diet with $40 \%$ energy as fat. For a man age 30 years, FFM $60.0 \mathrm{~kg}, \mathrm{FM} 15.0 \mathrm{~kg}$ and $\mathrm{EI}=\mathrm{EE}=13.0 \mathrm{MJ} / \mathrm{d}$, this implies a reduction of $\mathrm{EI}$ by $1.8 \mathrm{MJ} / \mathrm{d}$. The results of the simulation model and a linear model, assuming no changes in PA, are after 26 weeks: FFM and FM of 58.4 and $10.2 \mathrm{~kg}$, and 54.8 and $6.1 \mathrm{~kg}$ respectively. After 52 weeks the respective values are: FFM and FM of 57.3 and $7.1 \mathrm{~kg}$, and 43.3 and $0.0 \mathrm{~kg}$. A nearly twofold difference between the changes of FFM and FM and thus the energy content of the body calculated with the linear model and, the more realistic, simulation model (Fig. 2). Thus the simulation model can teach subjects about real EI and EE and about consequences of changes in EI and EE for FM and FFM. Starting a simulation with data on EI from a dietary record and data on EE from an activity budget usually results in a negative energy balance. Most subjects, especially overweight subjects underestimate EI (Schoeller, 1990; Westerterp et al. 1992 b). In a group of students (twenty-four females and seven males) starting a simulation run with the model with individual information on recorded intake and recorded physical activity, EI was significantly lower than EE $(P<$ 0.001 ; Wicoxon signed rank). Additionally, the discrepancy between EI and EE was higher in subjects with a higher body mass index (Pearson $r 0.56, P<0.001$ ).

\section{DISCUSSION}

The agreement of the simulation with observed values for BM and FM after a manipulation of EI or EE can be judged in units of weight or in units of energy. The latter allows combination of the two variables using the energy equivalents of the model, i.e. a change in FM has an energy equivalent of $38 \mathrm{MJ} / \mathrm{kg}$ and a change in BM minus $\mathrm{FM}$ is a change in FFM with an energy equivalent of $6 \mathrm{MJ} / \mathrm{kg}$. Table 5 shows the discrepancy between predicted and observed changes related to EI and EE over the observation interval. Mean discrepancies for the three studies between simulated and observed results are within the measurement precision of EI, EE and body composition (see below).

Obviously there are two possible explanations for discrepancies between observed and simulated results. First, the input data on FFM, FM, EI and EE have a limited degree of accuracy. The accuracy of body composition data is difficult to assess as in vivo comparison with true values is impossible. The estimated precision of changes in FM and consequently 
Table 5. Differences between measured and simulated energy content of the body $(\Delta E)$ in $(A)$ the study of Heyman et al. (1992), (B) the study of Diaz et al. (1992) and (C) the study of Bingham et al. (1989)

\begin{tabular}{lrrrr}
\hline & & \multicolumn{3}{c}{$\Delta \mathrm{E}(\mathrm{MJ})$} \\
\cline { 2 - 5 } & Study & Mean & SD & \multicolumn{1}{c}{ Range } \\
\hline A & 4 & - & - \\
B & 8 & 82 & -67 to 128 \\
C & -36 & 59 & -109 to 52 \\
\hline \hline
\end{tabular}

in FFM is at best between 1 and $2 \mathrm{~kg}$ (Murgatroyd \& Coward, 1989). All three studies included provisioning of a fixed diet over the entire observation interval. Thus, EI was calculated assuming that subjects consumed the food provided and did not consume additional food. EE was calculated as the mean of the value measured at the start and at the end of the observation interval on the assumption that any changes like the decrease through energy restriction or the increase through overfeeding or training were gradual and not instantaneous from the start of the intervention. Second, the model is based on assumptions and general equations including biological variation. It is difficult to estimate the effect of uncertainties in the separate components of the model. The resulting estimates are possibly the maximum one can obtain.

Unfortunately there are very few well-controlled studies on the consequences of a manipulation of EI or EE for FM and FFM in man. Measuring EI always interferes with a subject's behaviour under normal living conditions. Measuring EE is even more demanding when subjects are observed in a respiration chamber. The alternative, measuring EE with doubly-labelled water, is prohibitively expensive for long-term or largescale application. Thus, three studies were available to validate the model with an intervention ranging from 3 to 9 weeks. The longer the study the lower the precision of the data on EE. Heyman et al. (1990) measured EE over a $10 \mathrm{~d}$ baseline and the full $21 \mathrm{~d}$ intervention interval. The other two studies measured EE over a baseline interval and the last 2 weeks of the 6- and 9-week intervention intervals and figures for the other weeks had to be calculated by interpolation.

The vast literature on the effect of energy restriction on FM and FFM is unfortunately not suitable to validate the model. Only the referred study of Heyman et al. (1992), using mild and short-term energy restriction, measured EE. Surprisingly up until now none of the slimming studies have included measurements on EE. If any, separate components of EE are measured. Keys et al. (1950), restricting EI in thirty-two men from 14.6 to $6.6 \mathrm{MJ} / \mathrm{d}$ for 6 months in the classical Minnesota experiment, did not measure EE either. Only since the introduction of the doubly-labelled water method to measure EE in man (Schoeller \& Van Santen, 1982) is it feasible to measure EE with sufficient accuracy under normal living conditions. It is a matter of time before more studies on the effect of energy restriction on energy balance including EE measurements with doubly-labelled water appear.

\section{REFERENCES}

Ainsworth, B. E., Haskell, W. L., Leon, A. S., Jacobs, D. R., Montoye, H. J., Sallis, J. F. \& Paffenbarger, R. S. (1993). Compendium of physical activities: classification of energy costs of human physical activities. Medicine and Science in Sports and Exercise 25, 71-80. 
Apfelbaum, M. (1978). Adaptation to changes in caloric intake. Progress in Food and Nutrition Science 2, 543-559.

Bingham, S. A., Goldberg, G. R., Coward, W. A., Prentice, A. M. \& Cummings, J. H. (1989). The effect of exercise and improved physical fitness on basal metabolic rate. British Journal of Nutrition 61, 155-173.

Diaz, E. O., Prentice, A. M., Goldberg, G. R., Murgatroyd, P. R. \& Coward, W. A. (1992). Metabolic response to experimental overfeeding in lean and overweight healthy volunteers. American Journal of Clinical Nutrition $56,641-655$.

Forbes, G. B. (1987). Lean body mass-body fat interrelationships in humans. Nutrition Reviews 45, $225-231$.

Heyman, M. B., Young, V. R., Fuss, P., Tsay, R., Joseph, L. \& Roberts, S. B. (1992). Underfeeding and body weight regulation in normal-weight young men. American Journal of Physiology 263, R250-R257.

James, W. P. T. (1985). Appetite control and other mechanisms of weight homeostasis. In Nutritional Adaptation in Man, pp. 141-154 [K. Blaxter and J. C. Waterlow, editors]. London: John Libbey.

James, W. P. T., McNeill, G. \& Ralph, A. (1990). Metabolism and nutritional adaptation to altered intakes of energy substrates. American Journal of Clinical Nutrition 51, 264-269.

Keys, A. J., Brozeck, J., Henschel, A., Mickelson, O. \& Taylor, H. L. (1950). The Biology of Human Starvation. Minneapolis: University of Minnesota Press.

Murgatroyd, P. R. \& Coward, W. A. (1989). An improved method for estimating changes in whole-body fat and protein mass in man. British Journal of Nutrition 61, 311-314.

Prentice, A. M., Goldberg, G. R., Jebb, S. A., Black, A. E., Murgatroyd, P. R. \& Diaz, E. O. (1991). Physiological responses to slimming. Proceedings of the Nutrition Society 50, 441-458.

Schoeller, D. A. (1990). How accurate is self-reported dietary energy intake? Nutrition Reviews 48, 373-379.

Schoeller, D. A. \& van Santen, E. (1982). Measurement of energy expenditure in humans by doubly labeled water method. Journal of Applied Physiology 53, 955-959.

Schutz, Y., Bessard, T. \& Jéquier, E. (1984). Diet-induced thermogenesis measured over a whole day in obese and nonobese women. American Journal of Clinical Nutrition 40, 542-552.

Stichting Nederlands Voedingsstoffenbestand (1989). NEVO Tabel. 's Gravenhage: Voorlichtingsbureau voor de voeding.

Stock, M. \& Rothwell, N. (1982). Obesity and Leanness. London: John Libbey.

Waterlow, J. C. (1986). Notes on the new international estimates of energy requirements. Proceedings of the Nutrition Society 45, 351-360.

Westerterp, K. R., Meijer, G. A. L., Janssen, E. M. E., Saris, W. H. M. \& ten Hoor, F. (1992a). Long-term effect of physical activity on energy balance and body composition. British Journal of Nutrition 68, 21-30.

Westerterp, K. R., Verboeket-van de Venne, W. P. H. G., Meijer, G. A. L. \& ten Hoor, F. (1992b). Self-reported intake as a measure for energy intake, a validation against doubly labelled water. In Obesity in Europe '91, pp. 17-22 [G. Ailhaud, B. Guy-Grand, M. Lafontan \& D. Ricquier, editors]. London: John Libbey.

World Health Organization (1985). Energy and Protein Requirements, Report of a Joint FAO/WHO/UNU Expert Consultation. Technical Report Series no. 724. Geneva: WHO.

\section{A P PENDIX \\ Calculation of basal metabolic rate}

Basal metabolic rate (BMR) is calculated from fat-free mass (FFM) and fat mass (FM), and FFM is calculated from sex, age, height and body mass (BM) with equations generated by combining studies on adult healthy subjects presenting individual data on sex, age, height, BM, FM, FFM, BMR and energy expenditure (EE) (see References). Table A1 summarizes the relevant data.

Data are combined in a multiple regression analysis resulting in the equations:

$$
\operatorname{BMR}(\mathrm{MJ} / \mathrm{d})=0 \cdot 102 \mathrm{FFM}(\mathrm{kg})+0 \cdot 024 \mathrm{FM}(\mathrm{kg})+0 \cdot 85\left(n 190, r^{2} 0 \cdot 89\right),
$$

for women:

FFM $(\mathrm{kg})=-12.47-0.074$ age (years) +27.392 height $(\mathrm{m})+0.218 \mathrm{BM}(\mathrm{kg})$

for men:

$\left(n 105, r^{2} 0.81\right)$,

FFM $(\mathrm{kg})=-18 \cdot 36-0 \cdot 105$ age (years) $+34 \cdot 009$ height $(\mathrm{m})+0 \cdot 292 \mathrm{BM}(\mathrm{kg})$

$\left(n 85, r^{2} 0 \cdot 79\right)$. 
Table A1. Characteristics of the subjects

\begin{tabular}{|c|c|c|c|c|c|c|}
\hline & \multicolumn{3}{|c|}{ Women (n 105) } & \multicolumn{3}{|c|}{ Men $(n 85)$} \\
\hline & Mean & $\mathrm{SD}$ & Range & Mean & SD & Range \\
\hline Age (years) & 42 & 20 & $20-95$ & 42 & 19 & $19-80$ \\
\hline Height (m) & 1.63 & 0.08 & $1.38-1.81$ & 1.77 & 0.08 & $1.60-2.05$ \\
\hline Body mass $(\mathrm{kg})$ & 62 & 16 & $38-130$ & 80 & 24 & $55-215$ \\
\hline Fat mass $(\mathrm{kg})$ & 19 & 12 & $3-76$ & 19 & 17 & $2-128$ \\
\hline Fat-free mass (kg) & 42 & 6 & $29-60$ & 61 & 10 & $44-93$ \\
\hline BMR $(\mathrm{MJ} / \mathrm{d})$ & $5 \cdot 6$ & 0.9 & $3.4-8.2$ & $7 \cdot 6$ & 1.4 & $4 \cdot 7-12 \cdot 7$ \\
\hline $\mathrm{EE}(\mathrm{MJ} / \mathrm{d})$ & $8 \cdot 8$ & $2 \cdot 1$ & $4 \cdot 5-15 \cdot 1$ & $12 \cdot 7$ & $3 \cdot 0$ & $7 \cdot 8-21 \cdot 5$ \\
\hline EE:BMR & 1.57 & 0.25 & $1 \cdot 07-2 \cdot 25$ & $1 \cdot 70$ & $0 \cdot 30$ & $1 \cdot 13-2 \cdot 60$ \\
\hline
\end{tabular}

\section{REFERENCES}

Goldberg, G. R., Prentice, A. M., Coward, W. A., Davies, H. L., Murgatroyd, P. R., Sawyer, M. B., Ashford, J. \& Black, A. E. (1991). Longitudinal assessment of the components of energy balance in well-nourished lactating women. American Journal of Clinical Nutrition 54, 788-798.

Goran, M. I. \& Poehlman, C. T. (1992). Total energy expenditure and energy requirements in healthy elderly persons. Metabolism 41, 744-753.

Meijer, G. A. L., Westerterp, K. R., van Hulsel, A. M. P. \& ten Hoor, F. (1992). Physical activity and energy expenditure in lean and obese adult human subjects. European Journal of Applied Physiology 65, 525-528.

Pannemans, D. L. E. \& Westerterp, K. R. (1995). Energy expenditure, physical activity and basal metabolic rate of elderly subjects. British Journal of Nutrition 73, 571-581.

Prentice, A. M., Black, A. E., Coward, W. A., Davies, H. L., Goldberg, G. R., Murgatroyd, P. R., Ashford, J., Sawyer, M. \& Whitehead, R. G. (1986). High levels of energy expenditure in obese women. British Medical Journal 292, 983-987.

Prentice, A. M., Leavesley, K., Murgatroyd, P. R., Coward, W. A., Schorah, C. J., Blandon, P. T. \& Hullin, R. P. (1989). Is severe wasting in elderly mental patients caused by an excessive energy requirement? Age and Ageing 18, 158-167.

Roberts, S. B., Heyman, M. B., Evans, W. J., Fuss, P., Tsay, R. \& Young, V. R. (1991). Dietary energy requirements of young adult men, determined by using the doubly labeled water method. American Journal of Clinical Nutrition 54, 499-505.

Schulz, L. O., Alger, S., Harper, I., Wilmore, J. H. \& Ravussin, E. (1992). Energy expenditure of elite female runners measured by respiratory chamber and doubly labeled water. American Journal of Applied Physiology 72, 23-28.

Schulz, S., Westerterp, K. R. \& Bruck, K. (1989). Comparison of energy expenditure by the doubly labeled water technique with energy intake, heart rate and activity recording in man. American Journal of Clinical Nutrition 49, 1146-1154.

Westerterp, K. R., Meijer, G. A. L., Janssen, E. M. E., Saris, W. H. M. \& ten Hoor, F. (1992). Long-term effect of physical activity on energy balance and body composition. British Journal of Nutrition 68, 21-30.

Westerterp, K. R., Saris, W. H. M., Soeters, P. B. \& ten Hoor, F. (1991). Determinants of weight loss after vertical banded gastroplasty. International Journal of Obesity 15, 529-534. 